\title{
Massification in Ghanaian Higher Education: Implications for Pedagogical Quality, Equity Control and Assessment
}

\author{
Stephen Ntim ${ }^{1}$ \\ ${ }^{1}$ Faculty of Education, Catholic University of Ghana, Sunyani, Fiapre, Ghana, Western Africa \\ Correspondence: Stephen Ntim, PhD; M.Phil; M.A; B.Ed, Faculty of Education, Catholic University of Ghana, P.O. \\ BOX 363, Sunyani, Fiapre, Ghana, Western Africa.
}

Received: January 15, 2016

Accepted: February 3, $2016 \quad$ Online Published: February 19, 2016

doi:10.5430/irhe.v1n1p160

URL: http://dx.doi.org/10.5430/irhe.v1n1p160

\begin{abstract}
This paper examined the quality of higher education in Ghana within the context of significant educational expansion in institutions of higher learning. It identifies bottlenecks in Ghanaian Public Higher Education impairing Government's policy on Higher Education to expand access without compromising quality monitoring. Social justice and economic sufficiency discourses in Higher Education as a right have precipitated massive student intake. Large student enrolment however has not correlated with requisite funding leading to staff attrition rate, deterioration of physical infrastructure etc. This mismatch between massive student intake and dwindling number of academic staff and poor infrastructure contributes to undermining pedagogical quality, equity and effective student assessment. Findings from this survey suggest even though quality assurance issues are on course in Ghanaian universities, nevertheless, unless there is a new paradigm to funding public universities, teaching quality, equity and student assessments can become undermined.
\end{abstract}

Keywords: academic staff, poor infrastructure, pedagogical quality, equity, assessment

\section{Introduction}

The academic changes of the latter part of the last century as well as that of the early part of this $21^{\text {st }}$ century have precipitated a critical redesigning of the character of institutions of higher learning, especially the university across the globe. Extensive increases in numbers of programs as well as institutions of higher learning operating internationally grew astronomically high with countries of Asia such as Qatar, Singapore and the United Arab Emirates being typical examples. These countries embarked on internationalization of higher education as essential part of national policies. Prestigious foreign universities were recruited to establish campuses locally with the ultimate aim of expanding access for local students. Less endowed countries as well as academic institutions that are resource-deprived, opportunities for such global engagement internationally can be extremely burdensome (Altbach et al. 2009). Growing recognition of higher education as means towards upward social mobility has become heightened especially from the developing economies. This increased awareness of the link between higher education and upward mobility has led to the following: increasing diversified higher education, the de-monopolization of higher education, (especially university education in Africa since the mid 1990's from central government) and the increasing participation of the private sector in the provision of higher education, the incremental access to higher education as a fundamental right etc. All these have contributed to massification in higher education in many parts of the world. Indeed, massification is not a new concept in higher education. Nevertheless, globally, for the past one and a half decades, it has become so astronomical that most institutions of higher learning have no choice but to begin to wrestle with its implications especially from the point of view of pedagogical quality, equity control and assessment as well as funding.

Understandably, higher education has become and continues to become a competitive enterprise. In many countries worldwide, increasing student numbers have accelerated the competition for scarce places in universities. Admissions to high ranking universities continue to become more and more difficult because most of these universities have to maintain their high ranking status in order to compete for private as well as governmental funding. Historically, competition has always been a force to contend with in the academia so as to promote excellence, but, at the same time it can also contribute to a decline in the overall mission and traditional values of the academic community. 


\section{Statement of Problem}

In Ghana, it is estimated that within a period of thirteen (13) years, that is from 1983-1996, the total enrolment in universities and polytechnics increased by $162 \%$. The University of Ghana (the premier university) alone is estimated to have had an unprecedented increase in student enrollment culminating in its current population of about twenty eight thousand, four hundred and eighty two $(28,482)$ making it not only the oldest, but the largest of the eight public universities in Ghana, compared to a little of over sixteen thousand $(16,000)$ in 2002 and 2003. Of this number, about less than half has residential status due to poor infrastructural facilities. In addition, academic staff can hardly cope with the demands and pressure of work as a result of the increasing number of students in the classrooms. In some cases, lecturers handle more than one thousand (1000) students in such courses as Political Science, Philosophy, Psychology and Religious Studies in the first and second year undergraduates (http://www.ghanacommunity.com/forums/index.php?showtopic=5948).

This has Quality Assurance implications. Setting standards and ensuring quality control becomes especially problematic in the context of significant expansion and internationalization. The massive expansion in global enrolment since the last century coupled with the increasing diversity of students and institutions make quality assurance efforts become more and more complex. Contemporary global ethics, regional integration and economic blocks in many continents, increasing awareness of partnership between institutions of higher learning and versatility due to increasing mobility of academics and students, etc. continue to precipitate the need for recognized international benchmarks to guide comparison and evaluation of academic and professional qualifications.

In the midst of such significant expansion and massive growth in enrolment vis-à-vis the lack of increasing number of academic staff, how do Ghanaian institutions of higher learning ensure that pedagogical quality, equity control and assessment are not compromised and can compete with recognized international benchmarking? It is on record that most Ghanaian institutions of higher learning as at 2006 had only about 19 per cent of staff less than 40 years of age, about 34 per cent between the ages of 40 and 49 and 47 per cent above 50 years. Is the reduction in student intake the solution to the mismatch between massive enrolment and the dwindling number of academic staff and poor infrastructure as embarked on by some of the Ghanaian universities? In other words, quality in higher education especially in the areas of pedagogical quality, equity control and assessment used to be assured by the regulation and oversight of the Ghana National Accreditation Board (NAB) under the auspices of the Ministry of Education. Previously national higher education systems were restricted both in size and scope. In this sense, national rather than international standards were plausible and could be applied efficiently to limited number of institutions. However, the current global diversity, heavily characterized by increasing internationalization in higher education as well as the need to make university education accessible to as many young people as possible complicates the problem more for Ghanaian higher institutions at the level of global benchmarking.

Based on the above mentioned contemporary challenges of the perceived mismatch between increased student enrollment and the dwindling number of academic staff and poor infrastructure, the growing globalization and internationalization of institutions of higher learning, making internal/domestic evaluation less efficient as it used to be, as well as the global access of higher education as means of enhancing social mobility for some segments of population, how do institutions of higher learning in Ghana ensure that in all these contemporary challenges, pedagogical quality, equity control and assessment are not compromised?

\section{Research Objectives}

Following from the above mentioned problems, the objectives that guided this research paper were the following:

1) To assess measures put in place in selected Ghanaian institutions of higher learning and how they are confronting the mismatch between massive student-intake and dwindling academic staff.

2) To find out whether or not poor and insufficient infrastructure in our institutions of higher education has any effect on students' performance.

3) To investigate how Ghanaian institutions of higher learning are coping with the challenges of massive student enrolment and at the same time ensuring pedagogical quality.

4) To examine how these selected institutions control equity and students assessments.

\section{Research Questions}

The main research questions that this study investigated were:

1) What specific measures have been put in place in selected Ghanaian institutions of higher learning in responding to the mismatch between massive student-intake and dwindling academic staff? 
2) How are these institutions coping with the challenges of massive student enrolment and pedagogical quality?

3) What are the prescribed mechanisms used in these selected institutions to control equity and students assessments?

4) What structures have been put in place to cushion or offset the effects poor and insufficient infrastructure on quality culture?

\section{Significance of the Study}

The findings of this paper will be significant to stakeholders in higher education because of the inextricable link between higher education and human capital formation and the perceived nexus between institutions of higher learning and social mobility both in the developed as well as the developing nations. Even more so, this paper is significant especially because in Ghana, over the years, especially the mid 1980's and the early 1990 saw the beginnings of the reforms to the tertiary education system in Ghana. The Government White Paper titled 'Reforms to the Tertiary Education System in Ghana' published in 1991 consequent upon the University Rationalization Committee (URC) report in the mid 1980's made several proposals for the restructuring and re-organisation of tertiary education and tertiary educational institutions. This paper eventually led to the establishment of a Board of Accreditation with mandate in "furtherance of better management of tertiary education". The National Accreditation Board (NAB) was consequently established in 1993 with the enactment of PNDC Law 317, 1993. This Law was later replaced by the National Accreditation Board Act, 2007, Act 744 which became operationalized by Legislative Instrument, L. I. 1984 (Ntim, 2014). Thus, quality control since the mid 1980's has been high on the agenda of Ghanaian institutions of higher learning. This is to ensure that universities and other institution of higher learning continue to play their traditional role of maintaining academic excellence and quality. Within this context, the outcome of this paper will serve as means to compare whether or not Government's policy on quality higher education is on course within the context of significant massive student enrolment and limited public funding.

Again, the findings of this research will also be significant because of the contemporary link of markets in the provision of quality higher education. Since the last decades, the market has emerged as an instrument of public policy especially in the UK. Thatcher's government defined the three E's for the management of the public sector (Sizer 1990): Economy in the acquisition of resources, Efficiency in the use of resources, and Effectiveness in the achievement of objectives. In several countries around the globe, governments have also been experimenting with market-type mechanisms to force higher education institutions to compete for students, for funds, for research money. At the European level, for example, the Bologna Declaration, 'redefining the nature and content of academic programme', is transforming what were once state monopolies over academic degrees into competitive international markets (Dill et al 2004: 330; EUA 2007). Thus in the midst of all the above named contemporary factors in institutions of higher education there is indeed the justification to find out the link between contemporary social justice demand for access to higher education for all on one hand, and the mismatch between insufficient public funding on the other and their over-all implications for benchmarking and standard setting. The findings of this research paper will be significant to various stakeholders and regulatory bodies in higher education such as the Ghana National Accreditation Board, National Council for Tertiary Education (NCTE), the Ghana Ministry of Education, University Teachers Association of Ghana (UTAG), the Ministry of Finance, as well other policy makers.

\section{Theoretical Framework/ Literature Review}

\subsection{Defining Quality}

Defining what constitutes 'quality' in contemporary higher education characterized by increasing variability as well as internationalization becomes problematic. It is in this respect that Van Ginkel and Dias (2007:39) offer a more expansive definition. These authors make the claim that quality as used in higher education is a multi-dimensional concept that is functionally all-embracing in activities such as teaching and academic programmes, research and scholarship, staffing, students, buildings, facilities, equipment, services to the community as well as the academic environment. Consequently, present day definition of quality with respect to higher institutions is more an evolving process since the concept continuously adapts to changing contexts and exigencies.

Vlasceanu et al., (2007) also offer a definition reflecting the environmental complexity of higher education and in so doing indicating the multi-dimensional, multi-level, and dynamic concept which characterize the contextual settings of the typical educational model, to the institutional mission, and objectives as well as the particular standards in a given system, institutions programme or discipline. All this underscore the fact that ensuring quality in higher institutions is considered more as a process or an embedded culture in which key elements are assessed and measured. Within this embedded culture, concepts regarding performance, standards-setting, accreditation, norms, 
benchmarks, outcomes, and accountability intersect to constitute the basis of the quality culture coming out in higher education across boarders' (Adelman, 2009). The differences in exactly what is measured reflect the way individual countries and nations and cultures interpret quality.

\subsection{Quality as a Process}

At the close of the last century, policy frameworks for national higher education institutions were reformed. In emerging global economy, highly formed human capital has become a critical factor in both economic development and the competitive advantage of nations. Within the context of this global trend for advanced human capital, formal education and especially university education which used to be the prerogative of the privileged few is now shifting towards mass systems of higher education (Trow, 2005). As mentioned earlier, in Ghana for example, it is estimated that within a period of thirteen (13) years, that is from 1983-1996, the total enrolment in universities and polytechnics increased by $162 \%$. Thus the combined impacts of globalization, the need for enhanced human capital, leading to massification in higher institutions have changed fundamentally the traditional relationship between the state and institutions of higher education and motivated policymakers seeking novel means for assuring academic quality in higher education (World Bank, 2002) for the following five reasons: a) global demand for highly skilled and advanced human capital across countries as well as the proliferation of new academic programs for the advanced labor market have precipitated international recognition of credentials granted by a country's higher education. This has precipitated the need for established national policies for assuring and ensuring academic standards, $b$ ) increase in students' enrollment in higher education has given incentives for developing private institutions of higher learning as well as virtual universities. These new institutions continue to pose new challenges to national quality assurance. c) Third, the competitive forces of globalization and massification have made it imperative for institutions of higher education to be more responsive to the demands of rapidly changing labor markets as well as to student program interests. Consequently, higher education institutions in many countries in order to be flexible and a bit more autonomous from traditional state quality assurance regulations so as to respond to changing social demands begin to design new attractive academic programs, reconfiguring existing ones, and getting rid of archaic programs, d) Finally, social demand for higher education has reinvigorated students' desire to achieve benefits available to individuals with higher degrees. This private benefit of certification and academic degrees has shifted traditional debate on higher education finance from the public sector to private sector to pay a greater share of costs in higher education. This private sector cost bearing has increased public concern for higher education's accountability to ensure institutions provide educational value for money (cf. World Bank, 2002).

The above concern for accountability as a result of private financing has precipitated a paradigmatic shift from external review to internal peer review for evaluating quality in higher education, which is to rely on peers rather than government authorities to conduct evaluation process. Thus, contemporary quality assurance scheme begins with internal self-study or review of the institution being evaluated to undertake a thorough examination of its own internal practices, resources and accomplishments. The aim is to eventually measure the institutions performance in relation to its own mission and identifying ways for improvements. This process which is more operative today in Australia is referred to by the Australian Universities Quality Agency as "systematic and independent examination to determine whether activities and related results comply with planned arrangements and whether these arrangements are implemented effectively and are suitable to achieve objectives" (AUQA, 2008).

This internal peer review mechanism has become necessary also because of the increasing diversity and variability of institutions and their delivery systems. The framework for regulating quality assurance reflects one or more of the following criteria- quality as excellence, quality as fitness for purpose, and quality as enhancement or improvement. In other words, when quality is seen as a continuous process of assessment and improvement, regulating bodies begin to focus on whether or not institutions have adequate mechanisms in place to embed this dynamic process as part of the culture of higher education (Altbach et al, 2009).

Thus in contemporary discourse on quality assurance, a useful distinction is drawn between internal and external academic quality assurance. Internal quality assurance refers to those policies and practices whereby academic institutions themselves monitor and improve the quality of their education provision, while external quality assurance refers to supra-institutional policies and practices whereby the quality of higher education institutions and programs are assured. Individual universities have always possessed policies and practices designed to assure the quality of education, but academic institutions have also always operated within a national policy framework designed by the state to assure academic standards (www.unc.edu/ppaq) 


\subsection{Quality Assessment: Increasing Emphasis on Outcomes}

Assessing quality in Higher Education institutions over the years was purely that of quantitative data such as number of fulltime professors with terminal degrees, the quantity of available books in a given library, the ratio of students-lecturer, faculties publication output, etc. The paradigm has shifted considerably from quantitative data to qualitative achievement of students, especially on specific learning objectives that students have acquired as the main indicators of quality achievement. This new emphasis is crucial given the contemporary heightened attention to education accessibility and the fact the access can overshadow the quest for quality education. In addition, since 2006, OECD has introduced 'The Assessment of Higher Education Learning Outcomes' (AHELO). The purpose is for capacity building to assess teaching and learning. Assessing contemporary quality assurance is a combination of four core areas: a) physical and organizational characteristics: this involves observable characteristics as enrolment figures or the ratio of male to female students, b) education-related behaviors and practices: this deals with student-faculty interaction, academic challenge, emphasis on applied work, etc. c) psychosocial and cultural attributes: this involves career expectations of students, parental support, social expectations of higher education institutions, etc. and d) behavioral and attitudinal outcomes: students' ability to complete programmes of study, progression into graduate programs or success in finding a job, student satisfaction, improved student self-confidence, and self-reported learning gains claimed by students or their instructors (OECD, n.d.) Even though much has been accomplished in contemporary quality and accountability in learning outcomes, much is yet to be accomplished in assessing teaching (Altbach, et al. 2009).

\section{Current Study}

The literature reviewed above suggests that quality assurance is part and parcel of higher education. Indeed it is more a culture and must be constitutive part of contemporary higher education because of the increasing internationalization of benchmarking and standard-setting, the increasing variability of both students and staff across national boundaries, the contemporary emphasis on advanced human capital, the massification of students (irrespective of social and economic background) access to higher education, etc. Within all these contemporary scenarios of higher education, no institution of higher learning worthy of the name, can sacrifice pedagogical quality, equity and assessment. This paper therefore on the basis of higher education's accountability to education consumers' value for money, assesses the internal quality assurance with specific reference to teaching quality and learning outcomes in selected public universities in Ghana within the context of massive student intake, dwindling number of academic staff and poor infrastructure through a survey of the views of selected number of university teachers - senior academic members, senior administrative members and university students in Ghana.

\section{Research Methodology}

\subsection{Sample and Design}

Research design used for this study was the descriptive survey. This was considered appropriate for predicting the factors influencing the current situation of the focus of the study from the target population. The target population for this survey was university workers and students. This population was used because it clearly constituted the key informed respondents to the topic of the survey. Purposive, random and stratified sampling design from an estimated two hundred (200) university workers and students were sampled from Professors, Associate Professors, Senior lecturers, Lecturers, Senior Administrative staff and students, from four (4) out of the eight (8) public universities in Ghana where massification in student enrollment continues to be a challenge to academic auditing in four (4) out of the ten (10) administrative regions of Ghana: Ashanti, Central region, Greater Accra and the Brong Ahafo region. These four (4) regions were purposively located for this study because four (4) out of the eight (8) public universities are located in these regions. The rationale for the survey was explained to most of the respondents during telephone calls and in some cases personal contact that it was purely for academic purpose. After this, respondents were given a survey pack containing a consent form and the structured questionnaire. In the Ashanti and the Brong Ahafo regions, the researcher personally delivered and collected the self-administered questionnaires from respondents. In the other regions, the administration and collection of the questionnaire were done through a proxy. In all, there was good cooperation and a number of completed questionnaires were returned dully answered.

\subsection{Procedure and Measures}

The questionnaires were divided into different sections and each section sought to gauge respondents' perception on the research questions. The first part measured the personal data of respondents as follows: a) Respondents were asked to report information on their age, level of academic qualification (PhD, M.Phil; M.Sc, M.A), academic/administrative rank, years of engagement with university work as a student, etc.; (b) Personal vision of the 
goals of a university. Here the focus was on finding out respondents attributes of what constitutes benchmarks for standards setting in university in terms of their scale of preference. Hence the instrument used to assess this on the structured questionnaire was an adapted variant of the Attributes of the Intelligence Scale (Okagaki and Steinberg 1993). There was a total of eight items in the measure using Likert's 5-point scale ranging from 1 (strongly disagree) to 5 (strongly agree). Senior members Academic, Senior members Administrative, Junior Members Administrative and students perception of enrolment massification and implications for pedagogical quality, equity control and learning assessment were assessed in the structured questionnaire along the following four (4) measures: (1) institutional measures to respond to massive student intake and dwindling academic staff; 2) massive student intake and pedagogical quality; 3) prescribed mechanism to control equity and students assessment; 4) how to cushion the effects of insufficient infrastructure and academic quality.

\section{Results}

\subsection{Demographic Profile}

The total sample of respondents was two hundred (200) from the selected four (4) public universities and the breakdown is as follows: a) Senior Academic members with academic ranking ranging from Full Professors, Associate Professors, Senior Lecturers and Lecturers: sixty (60) respondents; b) Senior Members Administrative Staff, from Registrars, Senior Assistant registrars, Assistant Registrars: thirty (30) respondents; c) Junior Members Administration: administrative Secretaries, system analysts, twenty respondents (20); d) undergraduate students, forty-five (45) and e) postgraduate students, forty-five (45).

\subsection{Institutional Measures on Massive Student Intake and Dwindling Academic Staff}

This part of the survey investigated whether or not there were institutional measures in place in Ghanaian public universities to respond to the massive student intake and the dwindling academic staff. It is on record that in 1987 for example, there were just about nine thousand students $(9,000)$ in the then three (3) public universities: the University of Ghana, the Kwame Nkrumah University of Science and Technology and the University of Cape Coast. By 2010, Ghana had six (6) public universities with one hundred and fifteen thousand, three hundred and forty six students $(115,346)$. When one considers the burgeoning enrolments in newly created polytechnics in all the ten regions, colleges of education and other specialist institutions, tertiary enrolment in Ghana will be soaring above two hundred thousand $(200,000)$. This massive enrolment is against the backdrop of dwindling academic staff in most Ghanaian institutions of higher learning as at 2006 in which $19 \%$ of staff was less than 40 years of age, about $34 \%$ between the ages of 40 and 49 and $47 \%$ above 50 years in the University of Ghana.

This part of the survey then was meant to answer the first research question of this paper: What specific measures have been put in place in selected Ghanaian institutions of higher learning to respond to the mismatch between massive student intake and dwindling academic staff? Seventy percent $(70 \%)$ of the respondents (constituting some one hundred and forty (140) indicated that official measures were in place in their respective universities especially regarding staff development policy. Staff whether academic or administrative were encouraged to upgrade their skills to come back to the university to work. This notwithstanding, many of the respondents still submitted that they were not sure whether the rate and frequency of staff development output per se was enough to close the mismatch between the increasing massive students enrolment and the dwindling academic staff. Therefore, they were of the view that institutionally, yes, staff development policy was there as mandatory in all institutions of higher learning, but they have their doubts, if in reality this policy was helping to offset the contemporary challenges of massive student intake and the dwindling number of academic staff. Besides, the number of years or the duration that staff members may need to undergo upgrading training exacerbates the mismatch. Thirty of the respondents (constituting 15\%) indicated that there were no institutional measures while the remaining $15 \%$ were not sure whether institutional measures were in place or if 'distance education' as introduced in some of the universities was likely to curtail the mismatch. This was because in their view, even distance education needed some 'site meeting' and the same mismatch between massive student number and dwindling academic staff would not be solved.

\subsection{Massive Student Intake and Pedagogical Quality}

Generally students' literacy skills, general academic achievements, attitude, behaviors and experiences of schooling are influenced by their background as well as their intake characteristics. This notwithstanding, the magnitude of these environmental and biological effects is likely to become less significant when compared with class/teacher effects. In other words, from the kindergarten up to the university, the quality of teaching and learning is by far the most salient influences on students' cognitive, affective and behavioral outcomes irrespective of gender or backgrounds. Indeed there is copious research evidence indicating that what matters most in any educational institution is the quality of 
teachers and teaching that is supported by strategic teacher professional development. It is also on record that massive student intake is predicted to undermine effective teacher-student classroom interaction and therefore likely to impair pedagogical quality. The data on this variable in the survey indicated that overwhelming majority of respondents, $95 \%$ (constituting 190 respondents) were of the view that massive student intake indeed undermines pedagogical quality for obvious reasons: it impairs one to one teacher-student interaction, it undermines attendance control, it exerts stress on teacher especially giving and correcting assignments, etc. The remaining $10 \%$ (constituting 20 respondents) were doubtful. Responding to a sub-question under this part of the survey regarding the oversight responsibility of ensuring quality teaching whether it was at the departmental, faculty or the university, almost all respondents $98 \%$ (representing 196 respondents) indicated it was at the departmental level.

\subsection{Prescribed Mechanisms to Control Equity and Students Assessments}

Public institutions of higher learning, especially the universities, of late tend to be exceptionally diverse and have students from other parts of the globe, especially from sister African countries unlike hitherto. This de facto means that public universities in Ghana have a mandated mission to provide access to every student who can benefit from the experience. However, access alone is insufficient. Equity goals and initiatives must address outcomes as well as access. Universities both public and private must examine whether students are succeeding at equitable rates and whether all ethnic cohorts are tracked to measure equitable outcomes on standard measures such as basic skills, course completion, transfer readiness, and degree and certificate completion. Thus Ghanaian and African Universities to compete in the global economy which is knowledge-based must maintain their push to make access to university equitable and then turn their energy toward achieving equitable outcomes across all demographic lines. In line with this, the purpose of this research survey question then was meant to find out the current rates of enrolment, transfer and completion rates, but also to ask where are the barriers in the public universities?. What are the institutional policies holding students back? The purpose is to see whether there are things about the way our public universities are organized that are unintentionally serving as obstacles to student success or whether the students need additional support in the form of mentoring, tutoring, group learning environments, or different configurations of the curriculum -all within the context of massive student intake. Fifty percent constituting one hundred (100) respondents said YES, there were prescribed mechanism to control equity and student assessment while the other half said NO there were no prescribed mechanisms.

\subsection{Offsetting the Effects Poor and Insufficient Infrastructure on Quality Culture}

There is no doubt that the success of teaching and learning is likely to be influenced by available resources both human and material. For example, schools without teachers, text books or learning materials will not be able to do effective job. Similarly, the availability of classrooms, libraries, school facilities, hostels, tables and chairs, and other infrastructure when they are insufficient as it usually occurs in large student enrolments can be an impediment to quality culture in universities. In this respect, this question was to examine how Ghanaian universities were offsetting the effects of insufficient infrastructure on quality culture within the context of massive student intake. The following were the responses from respondents: $85 \%$ (comprising 170 respondents) were of the view that much more needs to be done by central government even though some attempts have been made in some of the higher institutions but these are not enough. Insufficient infrastructure still continues to be the major obstacle to academic quality. Fifteen percent (that is 30 out of the 200 respondents ) also concurred that infrastructure is a perennial challenge on quality culture, not much is being done, but also made the point that private organizations need to complement the effort of central government.

\section{Discussion}

The over-all findings of this survey suggest that massification in Ghanaian public Higher Education continues to set limits to quality assurance issues, especially, in the areas of pedagogical quality, equity control and students assessment notwithstanding the conscious efforts to embed quality culture in all institutions of higher learning. Most of the respondents ( $70 \%$ constituting 140 respondents) admitted that there were official institutional measures to deal with on-going staff development as institutional policy. However, these same one hundred and forty (140) respondents were quick to explain that they were not sure this policy alone constituted enough measure to offset massive students' intake vis-à-vis the dwindling number of academic staff. Out of the remaining $30 \%$ of respondents on this same measure 15\% (30 respondents) clearly denied any institutional measures to cushion the effects of massive students' enrolment and decreasing number of staff and the other $15 \%$ were not sure. When the response of this $30 \%$ is balanced against the $70 \%$ admitting of institutional measures of staff development policy but quick to add that they were still doubtful as to whether or not this policy alone could offset the mismatch, one can make some plausible conclusion that there is still much to be done in this area besides the official staff development plan in all universities in Ghana. 
This finding corroborates the recent revelation by the National Council for Tertiary Education (NCTE) in Ghana that the over-all number of two thousand, six hundred and seventy six (2676) academic staff in all the eight (8) public universities is not adequate enough to teach and supervise the academic work of more than one hundred and twenty eight thousand, three hundred and twenty six students $(128,326)$ (http:/citifmonline.com/2015/02/19/lecturers-in-short-supply-in-public-universities/). In Ghanaian institutions of higher learning, especially the public universities, the ratio of academic population to the student population is six times more than the required internationally acceptable student-to-teacher ratio. In such areas as business programmes, it is estimated that student-teacher ratio is $161: 1$ as against the normal standard of 27:1. Medicine which is very stringent and accepts only the best among the best of Ghanaian young brains, student-teacher ratio stands at 30:1 as against the accepted ratio of 12:1

Thus, this trend of massive student enrolment as against decreasing number of academic staff has the potential to undermine pedagogical quality. The $95 \%$ response (comprising 190 respondents of the total 200 respondents) from this report that massive student intake impairs pedagogical quality is clear enough. It certainly reduces quality assurance culture. Quality teaching aimed at focusing on working out procedures of quality evaluation and assurance in such areas as monitoring students' learning progress can become compromised with large class size, even with the best teacher experience and evolution of universities' organizational culture towards a quality culture. Indeed, there is significant relationship between massive enrollment and teaching quality: classrooms become stuffy especially in our African socio-cultural context with poor ventilation; lecture theaters become overcrowded; laboratories become too small to accommodate students, etc. confirming the position of Polgreen (2007); teachers become not only overstretched especially in the area of continuous assessment to monitor each individual students learning progress, but also can be exposed to fatigue-related diseases.

Peer internal monitoring of teaching quality is a requirement (as far as Quality Assurance is concerned). In the view of the respondents, they were also not quite sure if this was happening in reality. Besides, this type of internal peer monitoring was more at the departmental/faculty levels and not at the university-wide level in the universities selected for this survey. Assuming that this response is anything to by, it implies that quality teaching and monitoring of students learning progress as an important element of Quality Assurance is known in almost all the universities. However, internal peer review monitoring as a university-wide concept that must be made mandatory, is yet to be made fruitful in some of the universities.

Higher institutions of learning also have the oversight responsibility to ensure equity and students' assessment. Equity has to do with finding out about current rates of students' enrolment, transfer, completion etc. but also to ask what institutional barriers are keeping students back as part of quality assurance issues in contemporary Higher Education. Response to this question in the survey was clearly divided: 50\% (100 respondents) said YES, there were prescribed mechanism while the other 50\% (100 respondents) also responded NO. This is an indication that even among the stratified purposive sampling of university staff from senior academic staff to students who participated in this survey there was no unanimity. Of course, in all universities there are computer software systems to track and monitor students graduation progress, from Level 100 to postgraduate. Universities administration can track the rate of completion of those who abandoned their respective course programmes, etc. This might explain the $50 \%$ YES. But is this enough? How do universities assess extra curricula activities of students with special problems from home backgrounds that can put constraints on students' academic performance? How do universities ensure both formal interactions in class, counseling sessions and the library as well as in office hours student mentoring and tutorials? In short, university administrators, registrars etc. can track all the information needed on students, but may not be helpful when dealing one on one with mentoring and counseling students especially in these situations of massive enrolment with diversified student background. In short, responding to individual specific needs of students to ensure equity of all students irrespective of social, economic, ethnic backgrounds which are all core elements of quality assurance culture and assessing them from these backgrounds are likely to be undermined with massification.

\section{Constraints}

The findings of this survey cannot be said to be absolute. They are constrained by the following three (3) limitations: a) the fact that the study was conducted only in four (4) out of the ten (10) administrative regions of Ghana notwithstanding the explanation that the reason for the choice of location was for easy sampling as well as the fact that four (4) of the eight (8) public universities are located in these study area is also a weakness; b) The second constraint of this paper is the fact that the survey was conducted in only four (4) out of the eight (8) public universities; and c) because the study area was delimited to only four (4) regions, the purposive random sampling of the population was also limited to only these four (4) public universities within these four areas only and not the entire eight (8) public 
universities. All these notwithstanding, the findings from this study give some critical indicators of what actually obtains in the public higher education system in Ghana within the context of significant educational expansion in the last decade, which if not contained, are likely to undermined pedagogical quality.

\section{Policy Implications: Quest for New Paradigms in Funding Ghanaian Higher Education}

The above constraints notwithstanding, the findings above have policy implications, namely, the quest for new paradigms to fund Ghanaian Higher Education to implement Government policy on academic access without compromising quality (cf. Alison, 1999). The dynamics in higher education provision across the globe has changed considerably partly due to globalization and the extensive use of market mechanisms as means to promote competition between educational institutions in order to increase efficiency and maximize the provision of social benefits. A new redefinition in the nature and content of academic programmes has transformed state monopolies over academic degrees into competitive international markets. This market implication requires higher education to be competitive in international market by ensuring a culture of quality assurance such as pedagogical quality, equity control and student assessment among many others. The same market operations that make it imperative for Higher Education to be efficient through quality assessment have simultaneously also precipitated global wider economic benefits of education. Thus the economic/market as well as the social justice discourse in Higher Education have immense potential to address both economic development and social issues yet they also pose challenge to fragile and battling economies of less endowed countries.

The financial needs of individual universities far exceed the subsidies available. Growth in enrolments did not guarantee increases in the Cedi values of university funding in Ghana. For example, between 2006 and 2010, funding per student doubled to a modest $£ 970$ a year, less than the $40 \%$ of the amount recommended by the Ghana National
Council
for
Tertiary
Education

(https://www.timeshighereducation.com/news/ghanas-higher-education-sector-seeks-coherentnational-policies/2004

320.article). This ripple effect continues to be felt in the mismatch between massive enrollment and insufficient academic staff, poor infrastructural development and quality assurance issues. This calls for a new paradigm of public university funding, the purpose of which is to ensure development of affordable and sustainable Higher Education relevant to developmental agenda of the nation. The core feature of this funding framework needs to be goal-oriented in accordance with the following: a) national planning policy within the constraints of available funds in Higher Education budget, b) approved enrolment plans in individual universities, c) a reversion to the 1990's norm-based budgeting as opposed to current ad-hoc budgeting without due regard to the volume of activities performed by these public universities, d) appeal to public-private partnership in university funding.

\section{Conclusion}

This report has identified some of the institutional bottlenecks in Ghanaian Public Higher Education that impair Government's policy on Higher Education, namely, to expand access without compromising quality monitoring. As far back as 1986 and 1988, the University Rationalization Committee (URC) established a clear vision for the future of tertiary education: to avert the deterioration in conditions within the tertiary education in two main areas: (a) lack of financial provision and physical infrastructure and (b) relationship between the institutions and successive governments (Saywer 1994; Alison, 1999). Paradoxically, the social justice and economic sufficiency discourses in Higher Education, namely, that Higher Education is not a privilege but a right to every Ghanaian, the realization that Higher Education produces skills propelling individual labour productivity and a host of social, market and non-market benefits have led not only to the massive student intake in the public universities, but a proliferation of public universities from three (3) in number in the 1970 and the mid 1980's to eight public universities in 2015.

This massification in student intake has not correlated with the Cedi values of public university funding. This has contributed to high teacher attrition rate in the universities, deterioration of physical infrastructure etc. This mismatch between massive student intake and dwindling number of academic staff, poor infrastructure has contributed to undermining the core values of what universities stand for: pedagogical quality, equity and effective student assessment. The findings from this survey suggest that even though quality assurance issues are on course in most Ghanaian Universities, this notwithstanding, massification in students' enrolment can set limits to teaching quality, equity and assessments. There is therefore a need for a quest for new paradigm to fund public universities.

\section{References}

Adelman, C. (2009). The Bologna process for U.S. eyes: Re-learning Higher Education in the age of convergence. Institute for Higher Education Policy, Washington.

Alison, G. (1999). Tertiary education policy in Ghana. An assessment: 1988-1999 Report for the World Bank. 
Altbach, P. G., Resiberg, L., \& Rumbley L. (2009). Trends in global Higher Education: Tracking an academic revolution: A report prepared for UNESCO 2009 World Conference on Higher Education

Australian Universities Quality Agency (AUQA). n.d. AUQA Audit Reports: Self-accrediting institutions. Retrieved 14 December 2008 from http://www.auqa.edu.au/qualityaudit/qa/. Education relationships across three continents: The Winds of Change. Oxford: Pergamon/Elsevier Science Headington Hill Hall.

Dill, D., \& Soo, M. (2004). Transparency and quality in Higher Education markets. In Teixeira, P., Jongbloed, B., Dill, D. \& Amaral, A. (Eds.), Markets in Higher Education: Rhetoric or Reality? (pp. 61-85.) Dordrecht, Kluwer Academic Publishers.

EUA, European University Association. (2007). Embedding quality culture in Higher Education: A selection of papers from the $1^{\text {st }}$ European Forum for quality assurance: European University Association.

Ntim, S. (2014). Embedding quality culture in higher education in Ghana: quality control and assessment in emerging private universities. Journal of Higher Education Research, 68, 837-849.

Okagaki, L., \& Steinberg, R. (1993). Parental beliefs and children's school performance. Child Development, 64, 36-56.

Organisation for Economic Co-operation and Development (OECD), n.d., The assessment of higher education learning outcomes. $\quad$ Retrieved 20 May 2009, from http://www.oecd.org/document/51/0,3343,en_2649_35961291_40119475_1_1_1_1,00.html

Polgreen, L. (2007). Africa storied colleges, jammed and crumbling in the New York Timer.

Saywer, A. (1994). 'Ghana' relation between government and the universities in Higher Education.

Sizer, J. (1990). Funding councils and performance indicators in quality assessment in the United Kingdom. In Goedegebuure, L.C.J., Maassen, P.A.M. \& Westerheijden, D.F. (Eds.), Peer review and performance indicators - Quality assessment in British and Dutch Higher Education. Utrecht: Lemma.

Trow, M. (2005). Reflections on the transition from elite to mass universal access: Forms and phases of higher education in modern societies since WWII. In P. Altbach (Ed.), International handbook of Higher Education. Dordrecht, The Netherlands: Kluwer.

Van Ginkel, H.J.A., \& Rodrigues Dias, M.A. (2007). Institutional and political challenges of accreditation at the international level. In J. Tres (Ed.), Higher education in the world (2007). New York: Palgrave Macmillan.

Vlasceanu, L., Grünberg, L., \& Pârlea, D. (2007). Quality assurance and accreditation: A glossary of basic terms and definitions. Bucharest: UNESCO-CEPES.

World Bank. (2002). Constructing knowledge societies: New challenges for tertiary education. Washington, DC: World Bank. 